WellBeing International

WBI Studies Repository

2000

\title{
Fetal Pig: The High School Dissection Experience
}

\author{
Gracia Barr \\ Western Carolina University \\ Harold A. Herzog \\ Western Carolina University
}

Follow this and additional works at: https://www.wellbeingintlstudiesrepository.org/acwp_he

Part of the Educational Methods Commons, Humane Education Commons, and the Science and Mathematics Education Commons

\section{Recommended Citation}

Barr, G., \& Herzog, H. (2000). Fetal pig: The high school dissection experience. Society \& Animals, 8(1), 53-69.

This material is brought to you for free and open access by WellBeing International. It has been accepted for inclusion by an authorized administrator of the WBI Studies Repository. For more information, please contact wbisr-info@wellbeingintl.org.

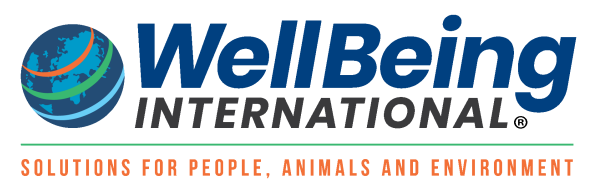




\title{
Fetal Pig: The High School Dissection Experience
}

\author{
Gracia Barr and Harold Herzog \\ Western Carolina University
}

\begin{abstract}
Using qualitative methods, we observed a series of fetal pig dissection sessions in a high school biology course and interviewed 17 students in the class. The students' responses to dissection varied considerably. Most felt that dissection was a positive experience, but a substantial minority viewed it primarily in negative terms. Almost all the students had some ambivalence about aspects of the fetal pig lab and believed that alternatives should be provided for students who object to the practice. We argue that dissection remains a viable educational tool but should be an optional rather than compulsory component of the curriculum.
\end{abstract}

Animal dissection has been a component of biology education in the United States since the early 1900s (Kinzie, Strauss, \& Foss, 1993). It is estimated that over five million vertebrates are killed each year to supply American classrooms with animals for dissection labs (Balcombe, 1996) and that approximately 75 to $80 \%$ of American children dissect at least once in high school (Orlans, 1993). Routine dissection of vertebrates at the precollege level has become controversial, and opponents object to the practice on both pedagogical and ethical grounds. It has been argued, for example, that dissection encourages rote memorization of anatomical details at the expense of more holistic educational experiences (Orlans, 1991), that it models cruelty rather than respect for life (Adkins \& Lock, 1994; Russell, 1996), and that it desensitizes students to animal suffering (Gilmore, 1991; Orlans, 1993; Shapiro, 1992). Shapiro (1991) claimed that dissection can be an emotionally traumatic experience, disturbing for the average adolescent.

Many biology teachers, on the other hand, feel that dissection provides a valuable hands-on experience that is critical to learning vertebrate anatomy (Keiser \& Hamm, 1991; Kinzie, Strauss, \& Foss, 1993; Lord, 1990; Mclnerney, 1993; Offner, 1995; Samsel et al., 1994). Further, advocates believe that dissection is the only way a student can really appreciate the "delicacy and fragility" of animal tissues (Biological Education Committee of the Royal Society and the Institute of Biology, 1975). Schrock (1991) and Chambers (1992) argued that dissection can be an exciting educational experience that can serve as a catalyst for decisions to enter science careers.

In the last 20 years, increasingly sophisticated alternatives to whole animal dissection have been developed. These include plastic models, computer programs, videotapes, videodiscs, and Internet web sites such as the Virtual Frog Dissection Kit (Kinzie, Larsen, Burch, \& Boker, 1996). Studies have found that students prefer computer-based alternatives over video or film alternatives (Kinzie et al., 1993) and that they learn more when the alternatives are interactive (Strauss \& Kinzie, 1991). Alternatives are 
particularly attractive to students who find dissection morally suspect or who are squeamish (Smith, 1994; Strauss \& Kinzie, 1991).

Many studies have compared anatomical / physiological knowledge of students who learned course material via dissection or an alternative. The results of these studies (most of which involved college or graduate students rather than secondary students) have been mixed. Balcombe (in press), a dissection opponent, recently reviewed 28 of these studies. He reported that in 16 studies there was equivalent learning in dissection and alternative groups, in 11 there was a significant difference in favor of the alternatives, and that in one study dissection resulted in significantly better students' performance.

Student reactions to dissection are often mixed. Strauss and Kinzie (1994), for example, found that threefourths of students who dissected a frog reported that they enjoyed the experience. However, an almost identical proportion of students who learned the material via the alternative also reported they enjoyed learning frog anatomy. In a retrospective study of Canadian college students, $27 \%$ of the participants reported having exclusively negative feelings about their high school dissection experience, $30 \%$ reported exclusively positive feelings, and 38\% reported ambivalent feelings (Bowd, 1993).

Despite the controversy surrounding vertebrate dissection in secondary schools, there are few studies of what actually happens in pre-college dissection labs and of student responses during and shortly after the experience (Lock, 1994). An exception is an ethnographic study by Solot and Arluke (1997) on dissection in sixth-grade classes in a private, urban, middle class school. The authors concluded that while students often developed positive attitudes toward dissection, potential harms outweigh the benefits in the middle school curriculum.

Recent research has shown that high school students bring a more sophisticated approach to scientific thinking than middle school students (Klaczynski \& Narasimham, 1998). Surprisingly, however, given the prevalence of dissection in American high schools, there is no previous research in which the reactions of high school student to dissection have been directly observed. Our goal was to characterize student experiences with dissection though classroom observations and interviews.

\section{Method}

We used qualitative methods including interviews and classroom observations to examine student responses to fetal pig dissection in a high school advanced biology course. The qualitative approach has been used effectively with other groups involved with sensitive issues involving the treatment of animals such as laboratory technicians (Arluke, 1988), veterinary students (Herzog, Vore, \& New, 1988), and firstyear medical students involved in a dog physiology lab (Arluke \& Hafferty, 1996). We supplemented our qualitative data by having the participants complete a written survey.

We observed fetal pig dissections in an elective upper level class (Biology II) in a rural high school in North Carolina. There were 22 students in the class, 17 of whom (12 females and 5 males) were interviewed about their dissection experience. They were in grades 10,11 , or 12 , with most in the 12th grade. Nine of the participants wanted to pursue a career in medicine, biology, or other field of science. Fetal pig dissection was a class requirement, and the students were not offered an alternative. Students dissected the fetal pig in groups of two to five per animal. They were given the option of wearing latex gloves during the procedures.

The teacher, Mr. Smith (pseudonyms are used throughout the paper), had taught biology for 13 years at the time we studied his class. He has an irreverent and amusing teaching style that makes him popular with students and keeps his classes full. He is a self-described animal-lover who keeps horses, dogs, cats, and parrots and belongs to several environmental organizations. Mr. Smith appeared to be 
ambivalent about dissection as a pedagogical tool. He told one of us $(\mathrm{HH})$ that he would prefer not to have students dissect. On the other hand, Mr. Smith clearly felt that it was an important component of the course. During one of the class sessions he expressed disdain for computer alternatives, asking the class, "Would you want to go to a doctor who had learned surgery using a computer simulation?" Thus, the students were clearly given the message that dissection was an integral part of the Biology II experience. At no point when we were present was there an extended serious discussion of ethical problems posed by the use of animals in education. Thus, the classroom environment clearly legitimated the use of fetal pigs as educational tools.

\section{Observation Procedures}

The fetal pig dissection took place toward the end of the term, and we visited the classroom once a week throughout the semester to accustom the students to our presence. The fetal pig dissection lasted nine class periods, each of which was observed. The class typically started with a brief introduction by Mr. Smith about the day's procedures: "Today you will need a scalpel, scissors, and dual-purpose bonecutter. You'll need to cut through bone today. It will crack and it will pop." During the class, Mr. Smith would usually circulate around the room, sitting at one table then the next, answering questions, showing incision techniques, and helping the students identify parts. Earlier in the semester the students had dissected a worm, a clam, a fish, and a frog.

\section{Interview Procedures}

Each of the participating students was interviewed individually using the interview guide approach (Patton, 1990). Semi-spontaneous conversations were built around a series of questions that focused on the students' reactions to dissection. Interviews typically lasted between 30 and 60 minutes and were audio taped. They were subsequently transcribed and analyzed for recurring themes.

Each participant also completed a brief, closed item questionnaire immediately after the interview. The survey was developed using the principles developed by Dillman (1978). The items included questions related to the participants' demographics, educational goals, and attitudes toward dissection : "If you had been offered a realistic alternative to dissection with no penalty would you have done it instead of dissecting the pig?".

This analysis of the dissection experience is based largely on the interviews. We have used direct quotations extensively in order to give the flavor of the students' responses. Before beginning our observations in this classroom, we observed dissections of various species in four biology classes in two other high schools and conducted pilot interviews with three biology teachers and two students.

It is common in ethnographic studies for the authors to discuss potential sources of bias. The first author had no experience with vertebrate dissection either in high school or college prior to this project. The second author remembers dissecting frogs in both high school and college biology courses. As a graduate student, he dropped an anatomy course after the first day of cat dissection when he realized that the instructor was serious when he told the students that they should learn all the muscles in the cat by the next class period. Trained in ethology, he has conducted both field and laboratory behavioral research with nonhuman animals.

\section{Results}

Most of the participants found the dissection lab to be a positive experience overall. In the written surveys, 12 of the 17 participants indicated that they enjoyed dissecting the fetal pig, whereas five participants indicated that they did not. Pro-dissection students gave a variety of reasons for liking the lab. 
Some were impressed with similarities between the pig's internal structures and their own. Several mentioned that they imagined how their internal organs looked as they examined their pig's viscera. During the "pig test," (the final exam) one boy touched and pointed to areas of his own body to help him remember where the parts were in the pig. Several students said that as they were examining a structure, they thought about diseases that they or relatives have had involving that organ. The worms, clams, frog, and fish that they dissected earlier in the course were simply not as interesting; working with a mammal seemed to be an important component of their inter- est in the pig. As Mac put it,

The clams and the frogs and everything are just not like us. It's kinda neat to see how I work.... Actually, it sort of came together, the two things. I mean, the fetal pigs really are a lot like humans. I could see the parallels between humans and animals.

Not all the students, however, were as enthusiastic as Mac about the dissec- tion process; for five of the participants it was a negative experience. These students often seemed uninvolved in the dissections. They rarely touched the animals. They would sit further away from the pig than their classmates and would typically assume the job of reading instructions from the lab manual to their more involved peers. Their disgust at certain procedures showed on their faces. As Sarah said when interviewed on the last day of the lab, "I looked forward to today because I knew it would be the last day I was going to do it. That's it."

\section{Ambivalence and Justifications}

For some of the participants, aspects of dissection evoked considerable moral and emotional ambivalence. When asked about her reactions to cutting into the pig, Joann said,

Well, I filled up with tears actually because I could look at it (the pig) as a baby. A life that's taken.... When the pigs were first handed to us, I filled up with tears.... But I can do the cutting; I'm usually the one that does stuff like that because I feel I'll benefit from it. But initially, I guess I was just upset about the whole idea.... It was definitely mixed emotions because it does interest me. I am interested in it, but thinking back on the fact that it is a life form, I get upset, you know. I'm distraught over that thought.... Yeah, I think it stays with me.... I go home and talk about it with my mom and tell her what all is going on.

Many of the students who initially experienced guilt or apprehension developed strategies to cope with their feelings as the labs progressed. As in the case of medical students engaged in a "dog lab" (Arluke \& Hafferty, 1996) and sixth graders dissecting fetal pigs (Solot \& Arluke, 1997), most students eventually set their feelings aside using various distancing mechanisms. They devised justifications for their use of the animals and came to see the dissections as beneficial. Edward, for example, said, "It was gonna happen anyway. I mean, the pigs were gonna be killed anyway. It didn't matter, so you might as well get a good education and make the most of their unfortunate death."

On two occasions we observed students covering the face of animals they were dissecting with paper towels - once during pilot observations of a cat dissection and again during the fetal pig lab. Joann, a member of the fetal pig group, told us,

Every time we've worked on it (the pig) the face was covered. I couldn't cut the face. I could watch, and once the face was cut it didn't look like a pig anymore, and I could deal with that because it looked like - you know - a scientific experiment to me. But seeing it lay there, I couldn't do the first cut, so my teammate did. 
Some students dealt with moral ambivalence simply by refusing to think about the ethical consequences of dissection. Andie, who typified this stance, said, "I don't think about it anymore. I guess that's what made me enjoy it. Because if I'd thought about it the whole entire time, I wouldn't have done anything. I wouldn't have touched it (the pig)."

\section{Ethical Issues}

In their surveys, 11 of the 17 participants either agreed or strongly agreed with the statement, "I have no ethical problems with dissection." Three participants were undecided, and three participants either disagreed or strongly disagreed. Some students believed that the majority of students in the class - those not headed for science careers - did not have a legitimate need to dissect the animals. Shannan illustrated this view, saying,

I don't really think it's right to raise animals for high school dissection because you don't learn all that much about it. I mean, if you're really serious about it, like in college or something, that's O.K., but in high school, you don't really learn that much.... If you have students dissecting, only half of them are really paying attention and doing it the right way. That's a waste of pigs that could be used for other students that are gonna learn something from it.

Sarah also found the dissections troubling. She believed pigs were put on Earth for a purpose, and the purpose is not high school dissection. While she was able to set aside these concerns in class and learn the animal's anatomy, she said she did not enjoy anything about the dissection sessions and was concerned that "God is going to punish me for cutting up a little pig. I think it was awful."

Rachel, on the other hand, initially had the same sorts of concerns as Sarah, but eventually she changed her mind about the ethics of dissection:

At first it was really weird. I could imagine it being alive, and I wanted to cry, but I didn't. And Mom just told me that, well, they were put there so they could be researched. That's why they were born and died - so we could learn about them.

\section{Mutilation}

Unlike Solot and Arluke (1997) who commonly witnessed mutilation among their middle school students, we rarely observed "recreational mutilation" by high schoolers. This may have been because Mr. Smith admonished the students with instructions such as, "Do not stick the probes in them. Do not mutilate them in any way. I will give you a zero. Don't even think about taking any body parts out of here. You must take this seriously." Most students did seem to take the labs seriously. This may have been because the course was an elective and the students were bright twelfth graders. Mutilation, however, occasionally did occur. Several participants mentioned that they were bothered when they saw other students mutilate their pig. On occasion, we observed students playing with body parts and probing and cutting when it was not called for. For example, Dennis, the class clown, once dangled a fetal pig heart over his mouth as if he would eat it, much to the amusement of his group members. At times he would try to cut on other groups' animals and would unnecessarily jab at his group's pig.

Distinctions between mutilation and educational procedures are not always clear. Some lab procedures could appear to the uninitiated as mutilation. This was particularly true of procedures involving the face of the pig such as cut- ting off of the animal's nose to expose the anatomy of the airway. Sarah said, "I just thought it was awful to cut off this little pig's nose." And Shannon said, 
I didn't like cutting the throat because, I mean, that was the most disgusting part because it wasn't just a clean cut. You had to, like, pull back the skin, shave off the skin. It was really nasty. That seemed more like mutilation than dissection.

On the other hand, "playful" interactions with organs can have unintended educational side effects. On one occasion, for example, the boys in a group cut out their pig's intestines and stretched them almost completely across the room, inadvertently demonstrating the extraordinary length of the viscera to the rest of the class.

\section{Dissection and the Nature of Life}

The experience that most Americans have with raw animal flesh is abstract - packages of meat at the supermarket. Herzog (1996) argued that dissection can serve as a values clarification process in which the student is confronted with larger questions related to the nature of what it means to be alive. We found no support for this view. We asked the students whether their dissection experience had facilitated their thinking about philosophical issues such as the nature of life and the relationship between humans and other species. None of the participants, even the most thoughtful and articulate ones, presented welldeveloped ideas or philosophies about these broader topics. For example, Edward, an advocate of dissection, indicated that he often thought about nature-oriented topics, but he did not believe that the dissection lab had influenced his views in any significant way:

I've always thought about nature and how most of the stuff that happens to animals is wrong. But as far as the dissections go, it hasn't posed any big "questions or answered any big questions. It answered a lot about how every- thing works; things that just particularly relate to inside the pig. It hasn't raised any questions of how we relate to something else. I really haven't given it all that much thought.

\section{The Question of Alternatives}

When interviewed, four of the students said they could have learned the material just as well using an alternative as by dissecting the fetal pig. Two of these said that while they enjoyed the fetal pig lab, they did not think that it was superior to an alternative as a learning experience. As one put it,

I think that I could have done the computer program dissection and have learned the same thing. I mean, I could have learned it just by pointing it out on the overhead. It just wasn't that real to me - the pig. It was interesting, but just as interesting as reading a book.

Another said,

I would have gotten just as much out of a computer simulation. On the computer, it can be 3-D'ish, where you can say, 'Oh, that looks bumpy and that looks smooth.' I think I would have been fine with a computer because you don't have the smell which makes you nauseated, and you don't have the stuff squirting out at you.

The majority of the students (12 of 17), however, believed they had learned anatomy better through dissection than they would have via an alternative method. They believed they comprehended more because they could cut skin, feel the textures of organs, and hear bones crack. As Edward put it,

I've seen those computer things before. You look from frame to frame - you'll see the intestines and the next frame the intestines will be gone and you'll see something in its 
place, and you won't know how exactly they got to where they did - what procedures were used to expose all the parts that you were needing to see. With the hands-on, you're exposing everything, actually moving stuff out of the way to get a better view of something. The hands-on just kills the computer program. The computer is good for the people who really can't take it. If they just can't take it, that's the next best thing.

Eden, who considered herself to be squeamish and who did not like dissection, said,

All your senses are really working when it's right in front of you. There's certain smells: If you smell it again, it brings back memories.... Whenever you open it, there's like liquid and blood and stuff and the models couldn't have that. And it was smooth and squishy, and I don't think models could do that.

Actually touching organs seemed to be an important component of the dis- section process. In their surveys, most of the participants indicated that they handled the pig "very much" and only two participants said they never handled it. During the labs we heard comments like "God, his liver is like a mushroom or something. His heart's kinda tough. Feel that," and, "Look at that. Ooh, it's got a weird texture."

Latex gloves were available for the students, but their use was optional. Eleven of the students in their survey responses indicated that they never wore gloves during the procedures.

Linda said,

I'd encourage people to not use gloves because somebody in our group used gloves and she would barely touch a thing. The textures and everything tell you a lot.... I just thought it was really neat, it was like everything was just so smooth.

\section{Squeamishness}

Most students quickly became at ease touching organs and fluids. There were, however, a few squeamish students in the class. Squeamish students crinkled up their noses as if they didn't like the smell. They avoided handling their group's pig and often looked bored, detached, and unhappy. In almost every group there was one student who had problems with dissection due to squeamishness. Squeamish students told us that they often felt nauseated during the dissections, and their visceral response to the procedures interfered with the learning process. For example, Chris said,

The first day, I thought I was just gonna be sick when Linda was actually slicing this pig open. I felt nauseated.... I don't handle blood and that kind of stuff very well. I was very glad that it didn't have blood in it. If it was a pig that had just died and had blood, I would not have been able to handle it. The organs themselves didn't make me queasy. When we cut open the stomach it was all gooey and stuff; that was gross. Before you cut it, and it's really smooth, that's pretty much O.K. I mean, the smell is bad, and you cut it, and it's gushing, and it squirts you. It's gross.

A few initially squeamish students adapted to dissecting the pigs as the labs went on, and they eventually came to appreciate the labs. Carrie said,

I am proud of myself. I feel like I've come a long way to be able to sit there and cut a pig. It has given me a lot of confidence just knowing that I can do that. It makes me feel like I could watch things now easier and get the real meaning of it instead of, 'this is really disgusting!' 
Almost every student mentioned that odor was a particularly unpleasant aspect of dissection. While the source of the smell was the chemical used to preserve the pigs, some of the students thought it was the odor of decom- posing flesh. Even some of the most enthusiastic dissectors said that it dampened their enjoyment of the experience. Robert described his reaction:

The first whiff of it is bad. And then you kind of get used to it. But then after about ten or fifteen minutes, you're sitting there cutting on the thing and it gets worse and worse and it starts.... Blah! Actually, it almost made me nauseous a few times. Not looking - just the smell of the preservative, so, it was just.... nauseating. But, that was what stood out the most. I do enjoy it; I just can't stand the smell.

\section{Recommendations on Opting Out}

We asked the students what they would recommend as a school policy regarding the use of an alternative instead of whole animal dissection. All the participants said that dissection should be an option rather than a requirement for students taking Biology II. Several felt that only certain students should be allowed to dissect animals - more mature students and those who plan to pursue careers in science. Robert's comments were typical:

I don't really think it should be required. If someone doesn't want to cut something open, I don't think they should be forced to.... There should be options. It shouldn't be like, 'O.K., now I've got to cut this or I'm gonna get a zero.' You're not gonna get a good grade. There just should be options. If someone doesn't want to do it, they shouldn't have to.

Many of the participants said that while they did not think that dissection should be required, they would encourage students to participate in the dissection labs. Before the semester started, Carrie had been unsure that she would be able to do the work due to her squeamishness. She said, however, that she had changed her opinion of dissection as a result of the fetal pig lab:

Before we started dissecting the pig, I would have been against it. Now in high schools, I'd probably be for it. Teenagers don't think a lot about killing an animal, or dissecting an animal, or seeing the inside of an animal. We just don't think about it that much until we have to do it, and it's just nothing we've ever done before - we've never experienced anything like that. So I kind of think it's something that people need to do.

\section{Dissection and Career Choices}

Some students reported that fetal pig dissection helped solidify their thinking about career paths. Several indicated that dissection raised their interest in a career in science or in a medically oriented field. The dissection experience bolstered their confidence, increased their interest in biology, and made them more convinced that they were suited for a career in the health sciences. It was a minor rite of passage in which they discovered that they could "handle" dissection and, by extension, intrusive medical procedures. As Andie put it,

Now I really want to go into the nursing field. Before doing our dissections, I thought that blood and stuff really bothered me, that I couldn't stand to look at it. I used to not stand to be around stuff like that, and now it just doesn't phase me at all... Now, I'm pretty sure I want to go into nursing or something that will deal with the stuff we've been working with.... It just came over me as something I wanted to do because I enjoyed it (the lab). I thought I couldn't deal with stuff like that. And now that I've actually been around it, I kind of enjoyed it. 
Dissection, however, had the opposite effect on career options for other students; it bolstered their convictions that they were not suited for a career in biology or the health sciences. Barbara said,

I didn't really get into the dissection a lot. I was there, and I learned about the pig and all.

But I don't think I ever really have had a passion for science. It's probably helped me

decide that I didn't.

\section{Discussion}

While the students in this classroom superficially had the same dissection experience, their psychological responses to the procedures were varied and complex. Twelve had largely positive responses to the labs, but for five the negative aspects of the experience outweighed the perceived benefits. Most students came away from the dissection experience with at least some ambivalence. Even the most pro-dissection students found certain aspects of the experience to be distasteful or disturbing. Likewise, many students who had negative responses to the labs found aspects of the dissections interesting, if not educational. For all the students, fetal pig dissection was a memorable experience.

Solot and Arluke (1997) argued that the potential harms of dissection out- weigh the benefits for middle school students. Our results suggest that this conclusion may not apply to high school age students. It is clear, however, that while dissection can be a powerful educational experience for some, it is an ordeal for others. Our view is that the potential pedagogical value of dissection does not justify the psychological cost to those for whom the process is morally offensive. We recommend that secondary students be routinely offered high quality alternatives to whole animal dissection. Biology teachers sometimes (and in our view, correctly) argue that dissection simulations are not particularly realistic and that some students will concoct bogus ethical objections simply to avoid labor intensive labs. Although these concerns are legitimate, we believe that it is more important to respect the principles of students who find dissection offensive than to worry about a few who may simply be lazy.

As always, there are limitations to this research. As is typical in qualitative studies, the observations are based on a relatively small sample - in this case in an Appalachian rural high school. Ethnographic studies of dissection in other educational settings will help determine the generalizability of our findings.

More important, our research does not address a fundamental issue - the degree that dissection is responsible for long-term changes in the ethical stance one takes toward other species. As Shapiro (1992) has indicated, most people have vivid memories of their first dissection lab. Bowd (1993) found that roughly equal numbers of people classify these recollections as primarily positive and primarily negative. Opponents of dissection sometimes argue that it desensitizes individuals toward the treatment of other species. It is conceivable, however, that dissection actually sensitizes some individuals toward animal welfare issues. Finally, it is possible that dissection in high school has no long-term influence on attitudes or behaviors directed at non-human animals. Further research is necessary to clarify the relationship between dissection and insensitivity toward other species.

\section{References}

Adkins, J. \& Lock, R. (1994). Using animals in secondary education: A pilot survey. Journal of Biological Education, 28, 348-352.

Arluke, A. \& Hafferty, F. (1996). From apprehension to fascination with "dog lab": The use of absolutions by medical students. Journal of Contemporary Ethnography, 25, 201-225. 
Arluke, A. \& Sanders, C. R. (1996). Regarding animals. Philadelphia: Temple University Press.

Arluke, A. B. (1988). Sacrificial symbolism in animal experimentation: Object or pet? Anthrozoos, 2, 183191.

Arms, S. A., \& Camp, K. (1994). Biology: A journey into life (3rd ed.). Ft. Worth: Harcourt Brace College Publishers.

Balcombe, J. (1996, July/August). Dissection and dissent. The Animals' Agenda, 23-24.

----- (1997). Student/teacher conflict regarding animal dissection. The American Biology Teacher, 59, 2225.

(in press). The use of animals in higher education: Problems, alternatives, and recommendations. Washington, DC: Humane Society Press.

Biological Education Committee of The Royal Society and the Institute of Biology (1975). The dissection of animals in school. Journal of Biological Education, 9, 146- 154.

Bowd, A. D. (1993). Dissection as an instructional technique in secondary science: Choice and alternatives. Society and Animals, 1, 83-89.

Chambers, C. H. (1992). Should students dissect frogs? NEA Today, 10, 39.

Dillman, D. A. (1978). Mail and telephone surveys. New York: John Wiley.

Gilmore, D. R. (1991). Politics \& prejudice: Dissection in biology education. American Biology Teacher, $53,211-213$.

Herzog, H. (1996, October). Dissection in the public schools: The view from the troubled middle. Paper presented at the National Association of Biology Teachers Convention, Charlotte, NC.

Herzog, H. A., Jr., Vore, T. L., \& New, J. C., Jr. (1988). Conversations with veterinary students: Attitudes, ethics, and animals. Anthrozoos, 2, 181-188.

Keiser, T. D., \& Hamm, R. W. (1991). Forum: Dissection. The Science Teacher, 58, 12-15.

Kinzie, M. B., Strauss, R., \& Foss, J. (1993). The effects of an interactive dissection simulation on the performance and achievement of high school biology students. Journal of Research in Science Teaching, $30,989-1000$.

Kinzie, M. B., Larsen, V. A., Burch, J. B., \& Boker, S. M. (1996). Frog dissection via the worldwide web: Implications for widespread delivery of instruction. Educational Technology Research and Development, 44, 59-69.

Klaczynski, P. A. \& Narasimham, G. (1998). Development of scientific reasoning biases: Cognitive versus ego-protective explanations. Developmental Psychology, 34, 175-187.

Lock, R. (1994). Dissection as an instructional technique in secondary science: Comment on Bowd. Society and Animals, 2, 67-74. 
Lord, T. R., (1990). The importance of animal dissection. Journal of College Science Teaching, 19, 330331. Mclnerney, J. D. (1993). Animals in education: Are we prisoners of false sentiment? The American Biology Teacher, 55, 276-280.

Offner, S. (1995, September). Cut here. The Executive Educator, 40. Orlans, F. B. (1991). Forum: Dissection. The Science Teacher, 58 (1), 12-15.

----- (1993) In the name of science: Issues in responsible animal experimentation. New York: Sage.

Patton, M. Q. (1990). Qualitative evaluation and research methods. Newbury Park, CA: Sage.

Russell, G. (1996). Biology: The study of life. The AV Magazine, CV(3), 2-7.

Samsel, R. W., Schmidt, G. A., Hall, J. B., Wood, L. D. H., Shroff, S. G., \& Schumacker, P. T. (1994). Cardiovascular physiology teaching: Computer simulations vs. animal demonstrations. Advances in Physiology Education, 11, S36-S46.

Schrock, J. R. (1991) Dissection. The Kansas School Naturalist. 36(3), 3-15.

Shapiro, K. J. (1991, November). The psychology of dissection. The Animals' Agenda, 20-21.

----- (1992, October). The psychology of dissection. The Science Teacher, 59, 43.

Smith, W. (1994). Use of animals and animal organs in schools: Practice and attitudes of teachers. Journal of Biological Education, 28, 111-118.

Solot, D. \& Arluke, A. (1997). Learning the scientist's role: Animal dissection in mid- dle school. Journal of Contemporary Ethnography, 26, 28-54.

Strauss, R. T. \& Kinzie, M. B. (1991). Hi-Tech alternatives to dissection. The American Biology Teacher, 53, 154-157.

----- (1994). Student achievement and attitudes in a pilot study comparing an interactive videodisc simulation to conventional dissection. The American Biology Teacher, 56, 398-402. 